\title{
Assessing the potential of wood welding for Australian eucalypts and tropical species
}

Benoit Belleville ${ }^{\mathrm{a}}$, Barbara Ozarska ${ }^{\mathrm{a}}$, and Antonio Pizzi ${ }^{\mathrm{b}}$

a The University of Melbourne, Faculty of Science, School of Ecosystem and Forest Sciences, Burnley campus,

500 Yarra Boulevard, Richmond, Victoria, Australia, 3121.

b The University of Lorraine, 27 rue Philippe Seguin, Epinal, France, 88051

*Corresponding author: Benoit Belleville The University of Melbourne, Faculty of Science, School of Ecosystem and Forest Sciences, Burnley Campus, 500 Yarra Boulevard, Richmond, Victoria, Australia, 3121, e-mail: benoit.belleville@unimelb.edu.au

\begin{abstract}
The wood welding potential of Australian and tropical species has been investigated. Optimized parameters for Eucalyptus saligna, Eucalyptus pilularis, Corymbia maculata, Ochroma pyramidale, and Tectona grandis were determined using a standard tensile strength test. The results confirmed the importance of density in the optimisation process. The grain direction also proved to have a significant impact on the welded joint strength of species featuring large wood rays or vessels in diagonal and/or radial pattern. Wood welding could therefore be an alternative for such species where gluing is required.
\end{abstract}

\section{Introduction}

Recent research advances have proven the high potential of wood welding for non-structural wood applications (Gfeller et al. 2003; Pizzi et al. 2004). Wood welding has the potential to improve production flow and flexibility by eliminating curing times for adhesive polymerization as well as multiple handling, resulting in more competitive products and significant economic, environmental and technical benefits for wood products industry. The interest of the present study was to assess the wood welding potential of high and low density species located outside that density spectrum and to assess the impact of density on the welding parameters. Specific objectives were (i) to assess the potential of wood welding for selected Australian eucalypts and tropical species (ii) to define optimal wood-dowel welding parameters for each studied species.

\section{Materials and methods}

The wood material was pre-conditioned until constant mass was reached in a conditioning room at $23^{\circ} \mathrm{C}$ and $65 \%$ relative humidity $(\mathrm{RH})$ before testing. Species selected for the study were Corymbia maculata (air dry density of $965 \mathrm{~kg} \mathrm{~m}^{-3}$ at $\left.12 \% \mathrm{MC}\right)$, Eucalyptus saligna $\left(784 \mathrm{~kg} \mathrm{~m}^{-3}\right)$, Eucalyptus pilularis $\left(925 \mathrm{~kg} \mathrm{~m}^{-3}\right)$, Tectona grandis $\left(598 \mathrm{~kg} \mathrm{~m}^{-3}\right)$, and Ochroma pyramidale $\left(136 \mathrm{~kg} \mathrm{~m}^{-3}\right)$ because of their availability as plantation timbers and commercial value.

Clear, straight-grained wood slats with dimensions $30 \mathrm{~mm}$ x $30 \mathrm{~mm}$ x 800-900 mm were selected, prepared, conditioned and used to prepare welded specimens. Commercially manufactured smooth wood dowels made from the same above-listed species (Porta Mouldings, Victoria, Australia) $9.45 \mathrm{~mm}$ in diameter and $100 \mathrm{~mm}$ in length were inserted into pre-drilled holes $25 \mathrm{~mm}$ in depth using a manually operated fixed base drill (McMillan BD16, 3/4 HP, Taiwan). Following insertion, the dowel excess was kept to provide a grip for tensile strength testing.

A comparative analysis of wood-dowel welding parameters was performed. The investigated parameters for all studied species were grain direction (tangential and radial equivalent to $0^{\circ}$ and $90^{\circ}$ to the growth rings, respectively), rotational speed (1230 and $1415 \mathrm{rpm})$ and ratio of dowel diameter to receiving hole $(1.11,1.26$, 
and 1.45), for 12 possible combinations per species. Fifteen specimens were prepared. Following welding, the slats with welded dowels were cut into smaller specimens and conditioned at $23^{\circ} \mathrm{C}$ and $65 \% \mathrm{RH}$ for 7 days prior to testing until MC of $12 \%$ was reached. Each specimen consisted of one dowel inserted into a wood substrate.

Optimal welding mechanical properties were determined from the dowel withdrawal strength using a standard tensile strength test (ASTM 2012) on a universal testing machine (Instron 5569, Massachusetts, USA). During the test sequence, the dowel excess was retained by a fixed wedge action grip while a load was applied to the wood substrate surface by a tension test fixture. Under a constant rate of $2 \mathrm{~mm} \mathrm{~min}^{-1}$, the withdrawal strength $\left(\sigma_{k}, \mathrm{MPa}\right)$ was calculated from the maximum load measured at break $\left(F_{\max }, \mathrm{N}\right)$ and the welded surface $\left(S, \mathrm{~m}^{2}\right)$ by the following equation:

$$
\sigma_{k}=\frac{F_{\max }}{S}=\frac{F_{\max }}{2 \pi r h}
$$

where $r=$ the pre-drilled hole radius (mm) and $h=$ the insertion depth (mm).

For optimisation purposes, factorial testing was used to analyze the effects of wood-dowel welding parameters on the mechanical properties of welded joints for each individual species. Test results were subjected to analyses of variance (ANOVA) using Minitab statistical software (v16.1.0).

\section{Results and discussion}

The analysis showed a significant interaction between species, rotational speed, and dowel/hole diameter ratio $(F$-value $=2.28)$. When considered individually, the analysis showed that the weldline strength was strongly influenced by the species used $(F$-value $=256.38)$. The ratio of dowel diameter to the receiving hole was the second most influential parameter $(F$-value $=53.90)$ followed by the rotational speed $(F$-value $=14.03)$. This interaction confirmed that a good weldline requires a fine balance between friction induced temperature at the interface, welding time, charring, and the quantity of material expelled from the interface (Belleville et al. 2013). In the case of high density species such as the ones used in the present experiment, welding using smaller dowel/hole ratio allowed using slower rotational speed and reducing welding time to limit charring and produced stronger joints. Dowel rotational speed has been demonstrated to influence the tensile strength of the welded joint (Pizzi et al. 2004; Rodriguez et al. 2010; Belleville et al. 2013). This parameter affects the temperature rise and the softening temperature of amorphous wood polymers. The longer the high-temperature welding time, the greater the odds of burning the wood at the welding interface.

When assessed individually most species performed well with the exception of Ochroma pyramidale. Eucalyptus saligna and Eucalyptus pilularis provided the best results with average maximal withdrawal strengths of $3.4 \pm 0.4$ and $2.8 \pm 0.2 \mathrm{MPa}$, respectively (Table 1). Tectona grandis achieved an average maximal withdrawal strength of $1.9 \pm 0.3 \mathrm{MPa}$ where Corymbia maculata attained 1.2 $\pm 0.6 \mathrm{MPa}$. Because of Ochroma pyramidale low density $\left(136 \mathrm{~kg} \mathrm{~m}^{-3}\right)$, the dowels simply crushed when fitted into pre-drilled holes, preventing friction and temperature to rise at the interface. Additional tests were conducted using notably higher dowel/hole diameter ratios or the wood nail concept (Ganne-Chedeville et al. 2005) without success. This observation appears to be similar to the cell walls collapsing issue noticed when using low density Norway spruce (Picea abies, Gfeller et al. 2003).

Tectona grandis. Both hole $(F$-value $=38.06)$ and grain direction $(F$-value $=23.18)$ individually had a very significant influence on the withdrawal strength. Unlike the other tested species, the withdrawal strength dropped significantly, with a 95\% confidence level, when welding using a 1.11 dowel to receiving hole diameter ratio. This can probably be explained by the lower density of Tectona grandis, when compared with the eucalypts, which limit the friction allowing temperature to increase at the weldline. Another possible reason might be the presence of oily extractives which could have migrated at the weldline affecting chemical reactions at the weldline. Tectona grandis was the only tested species where a radial insertion provided significantly better results. Anatomically, large wood rays which are commonly 4 to 10 seriate possibly limit the insertion tangentially in the substrate, producing more charring. Interestingly, no matter which rotational speed and ratio 
combination was selected greater results were obtained with a radial insertion. No interaction between factors has been found.

Eucalyptus saligna. A significant interaction between the rational speed and the ratio of dowel diameter to receiving hole has been found $(\operatorname{Pr}=0.014)$. From all tested species, the wood diffuse-porous Eucalyptus saligna with ray width from 1 to 3 cells was probably the most uniform and suitable species for wood welding from an anatomical point of view. Both 1.11 and 1.25 ratio settings provided similar results where a 1.45 ratio produced significantly weaker welded joints. A speed of $1230 \mathrm{rpm}$ provided significantly higher results compared to 1415 $\mathrm{rpm}$. The interaction can be explained by the fact that a higher rotational speed increases the temperature at the weldline, thus increasing charring. The same principle could be observed when using a 1.45 dowel/hole ratio which unduly extended the exposure of the weldline to high temperature causing charring.

Eucalyptus pilularis. A significant interaction between the rotational speed and the grain direction has been found $(\operatorname{Pr}=0.035)$. Interestingly, the dowel/hole ratio individually had a very significant influence $(F$-value $=$ 204.27) on the bondline strength although not interacting significantly with any other parameter. The withdrawal strength significantly increased as the pre-drilled hole diameter was increased, with the best results obtained using a 1.11 ratio. However, using a 1.11 ratio caused irregularities during the welding process with dowels sometimes not fully fitting in the pre-drilled holes. The situation was especially noticeable when using a speed of $1415 \mathrm{rpm}$. During a manual insertion, the increase of temperature allows the polymeric material at the top of the dowel to melt, easing the insertion of the dowel in the pre-drilled hole. The situation causes an acceleration of the insertion speed. However, in the case of high density species such as Eucalyptus pilularis and Corymbia maculata, the melting process is probably not fast enough to allow such acceleration, resulting in the dowel jamming midway in the pre-drilled hole. Hence, a rotational speed of $1230 \mathrm{rpm}$ appears to limit the acceleration of the insertion speed and would be more appropriate. Another aspect affecting the withdrawal strength might be the presence of vessels in diagonal and/or radial pattern, which might facilitate the insertion tangentially to the grain. This could potentially explain the interaction between the rotational speed and the grain direction. During the welding process, a large proportion of material was also expelled out of the weldline compared with the lighter species such as Eucalyptus saligna. Since a well welded bondline requires minimising the quantity of material expelled to allow the densification to provide good mechanical properties (Pizzi et al. 2004 ) it is not surprising that a 1.11 ratio provided better results.

Corymbia maculata. Like Tectona grandis, both the ratio of dowel diameter to receiving hole $(F$-value $=23.85)$ and the grain direction $(F$-value $=8.37)$ individually had a very significant influence on the mechanical strength of welded joints made of Corymbia maculata. Being the densest species tested $\left(965 \mathrm{~kg} \mathrm{~m}^{-3}\right)$, increasing the predrilled hole diameter eased the insertion of the dowel and reduced the welding time and charring. A tangential insertion always provided better results when compared with radial insertion for all tested combination. As the case with Eucalyptus pilularis the presence of vessels in diagonal and/or radial pattern probably eased the dowel insertion to a certain point. No interaction between factors has been observed.

\section{Conclusion}

The objectives of the present study were to assess the potential of wood welding for selected Australian eucalypts and tropical species and to define optimal wood-dowel welding parameters for each selected species. Most species performed reasonably well with the exception of Ochroma pyramidale. The results confirm the importance of density in the welding process. The optimal dowel to receiving hole diameter ratio was closely related to the density of the species used. For higher density species such as Eucalyptus pilularis and Corymbia maculata a 1.11 ratio proved to be optimal where similar results were obtained for Eucalyptus saligna using either a ratio of 1.11 or 1.25. As for Tectona grandis which density is similar to already studied European and North American species, a 1.25 ratio proved to be optimal.

A rotational speed of $1230 \mathrm{rpm}$ usually provided better results for all tested species notably by limiting charring caused by high temperature at the weldline. Using a lower rotational speed for high density species possibly allowed limiting the negative impact of high temperature on the weldline performance. The grain direction proved to have a significant impact on all tested species with the exception of Eucalyptus saligna. Interestingly, 
Eucalyptus saligna provided the best results from all tested species. Anatomical features such as large wood rays in Tectona grandis or vessels in diagonal and/or radial pattern in Eucalyptus pilularis or Corymbia maculata probably affected the withdrawal strength of the welded joint. Some chemical reactions caused by the polymeric material and other compounds presents in wood might also explain the differences observed between these species.

\section{Acknowledgements}

The authors acknowledge the financial support of the University of Melbourne. Thanks are extended to Porta Mouldings and Boral Timber for providing the material. Special thanks are owed to Zhexing Wang and Jamaludin Malik for their assistance with the laboratory work.

\section{References}

ASTM (2012) Standard test methods for evaluating properties of wood-base fiber and particle panel materials. ASTM D1037. American Society for Testing and Materials, West Conshohocken, PA, United States.

Belleville B, Stevanovic T, Pizzi A, Cloutier A, Blanchet P (2013) Determination of optimal wood-dowel welding parameters for two North American hardwood species. J Adhes Sci Technol 27 (5-6): 566-576.

Ganne-Chedéville C, Pizzi A, Thomas A, Leban J-M, Bocquet J-F, Despres A, Mansouri HR (2005) Parameter interactions in two-block welding and the wood nail concept in wood dowel welding. J Adhes Sci Technol 19: 1157-1174.

Gfeller B, Zanetti M, Properzi M, Pizzi A, Pichelin F, Lehmann M, Delmotte L (2003) Wood bonding by vibrational welding. J Adhes Sci Technol 17(11):1573-1589.

Pizzi A, Leban J-M, Kanazawa F, Properzi M, Pichelin F (2004) Wood dowel bonding by high speed rotation welding. J Adhes Sci Technol 18:1263-1278.

Rodriguez G, Diouf P, Blanchet P, Stevanovic T (2010) Wood dowel bonding by high-speed rotation welding Application to two Canadian hardwood species. J Adhes Sci Technol 24:1423-1436.

Table 1. Average maximal withdrawal strengths obtained for each set of welding parameters.

\begin{tabular}{lccccc}
\hline Species & Ratio $^{\text {a }}$ & $\begin{array}{c}\text { Rotational } \\
\text { speed (rpm) }\end{array}$ & $\begin{array}{c}\text { Grain } \\
\text { orientation }\end{array}$ & $\begin{array}{c}\text { Withdrawal } \\
\text { Strength (MPa) }\end{array}$ & $\begin{array}{c}\text { No. of } \\
\text { Replicates }\end{array}$ \\
\hline \hline Eucalyptus saligna & 1.11 & 1230 & Tangential & $2.8 \pm 0.6^{\mathrm{b}}$ & 8 \\
Eucalyptus saligna & 1.11 & 1230 & Radial & $2.9 \pm 0.3$ & 7 \\
Eucalyptus saligna & 1.11 & 1415 & Tangential & $2.6 \pm 0.4$ & 8 \\
Eucalyptus saligna & 1.11 & 1415 & Radial & $2.5 \pm 0.3$ & 7 \\
Eucalyptus saligna & 1.25 & 1230 & Tangential & $3.4 \pm 0.4$ & 8 \\
Eucalyptus saligna & 1.25 & 1230 & Radial & $2.8 \pm 0.7$ & 7 \\
Eucalyptus saligna & 1.25 & 1415 & Tangential & $2.0 \pm 0.2$ & 8 \\
Eucalyptus saligna & 1.25 & 1415 & Radial & $1.9 \pm 0.4$ & 7 \\
Eucalyptus saligna & 1.45 & 1230 & Tangential & $2.0 \pm 0.6$ & 9 \\
Eucalyptus saligna & 1.45 & 1230 & Radial & $1.8 \pm 0.6$ & 6 \\
Eucalyptus saligna & 1.45 & 1415 & Tangential & $1.3 \pm 0.6$ & 8 \\
Eucalyptus saligna & 1.45 & 1415 & Radial & $1.1 \pm 0.4$ & 7 \\
Eucalyptus pilularis & 1.11 & 1230 & Tangential & $2.7 \pm 0.3$ & 8 \\
Eucalyptus pilularis & 1.11 & 1230 & Radial & $2.8 \pm 0.2$ & 7 \\
Eucalyptus pilularis & 1.11 & 1415 & Tangential & $2.7 \pm 0.6$ & 8 \\
Eucalyptus pilularis & 1.11 & 1415 & Radial & $2.4 \pm 0.4$ & 7 \\
Eucalyptus pilularis & 1.25 & 1230 & Tangential & $1.4 \pm 0.2$ & 8 \\
\hline
\end{tabular}




\begin{tabular}{llllll}
\hline Eucalyptus pilularis & 1.25 & 1230 & Radial & $1.5 \pm 0.2$ & 7 \\
Eucalyptus pilularis & 1.25 & 1415 & Tangential & $1.5 \pm 0.3$ & 7 \\
Eucalyptus pilularis & 1.25 & 1415 & Radial & $1.5 \pm 0.2$ & 8 \\
Eucalyptus pilularis & 1.45 & 1230 & Tangential & $0.9 \pm 0.2$ & 7 \\
Eucalyptus pilularis & 1.45 & 1230 & Radial & $1.1 \pm 0.2$ & 8 \\
Eucalyptus pilularis & 1.45 & 1415 & Tangential & $1.2 \pm 0.2$ & 8 \\
Eucalyptus pilularis & 1.45 & 1415 & Radial & $1.1 \pm 0.3$ & 7 \\
Corymbia maculata & 1.11 & 1230 & Tangential & $1.0 \pm 0.3$ & 10 \\
Corymbia maculata & 1.11 & 1230 & Radial & $0.9 \pm 0.3$ & 5 \\
Corymbia maculata & 1.11 & 1415 & Tangential & $1.2 \pm 0.6$ & 9 \\
Corymbia maculata & 1.11 & 1415 & Radial & $0.7 \pm 0.2$ & 6 \\
Corymbia maculata & 1.25 & 1230 & Tangential & $0.6 \pm 0.3$ & 10 \\
Corymbia maculata & 1.25 & 1230 & Radial & $0.5 \pm 0.2$ & 5 \\
Corymbia maculata & 1.25 & 1415 & Tangential & $0.6 \pm 0.2$ & 9 \\
Corymbia maculata & 1.25 & 1415 & Radial & $0.5 \pm 0.2$ & 6 \\
Corymbia maculata & 1.45 & 1230 & Tangential & $0.5 \pm 0.3$ & 10 \\
Corymbia maculata & 1.45 & 1230 & Radial & $0.5 \pm 0.2$ & 5 \\
Corymbia maculata & 1.45 & 1415 & Tangential & $0.5 \pm 0.1$ & 10 \\
Corymbia maculata & 1.45 & 1415 & Radial & $0.2 \pm 0.1$ & 5 \\
Tectona grandis & 1.11 & 1230 & Tangential & $0.1 \pm 0.1$ & 8 \\
Tectona grandis & 1.11 & 1230 & Radial & $0.7 \pm 0.5$ & 7 \\
Tectona grandis & 1.11 & 1415 & Tangential & $0.4 \pm 0.3$ & 7 \\
Tectona grandis & 1.11 & 1415 & Radial & $0.6 \pm 0.4$ & 8 \\
Tectona grandis & 1.25 & 1230 & Tangential & $0.7 \pm 0.7$ & 8 \\
Tectona grandis & 1.25 & 1230 & Radial & $1.9 \pm 0.3$ & 7 \\
Tectona grandis & 1.25 & 1415 & Tangential & $1.2 \pm 0.8$ & 7 \\
Tectona grandis & 1.25 & 1415 & Radial & $1.6 \pm 0.3$ & 8 \\
Tectona grandis & 1.45 & 1230 & Tangential & $1.2 \pm 0.6$ & 8 \\
Tectona grandis & 1.45 & 1230 & Radial & $1.6 \pm 0.4$ & 7 \\
Tectona grandis & 1.45 & 1415 & Tangential & $1.4 \pm 0.2$ & 6 \\
Tectona grandis & 1.45 & 1415 & Radial & $1.6 \pm 0.6$ & 9 \\
\hline Ratio of doweldiameter & & &
\end{tabular}

${ }^{\mathrm{a}}$ Ratio of dowel diameter to receiving hole. ${ }^{\mathrm{b}}$ Standard deviation. 